\title{
The Effects of Testosterone Deficiency and Its Replacement on Inflammatory Markers in Rats: A Pilot Study
}

\author{
Kok-Yong Chin, ${ }^{1, *}$ and Soelaiman Ima-Nirwana ${ }^{1}$ \\ ${ }^{1}$ Department of Pharmacology, Faculty of Medicine, Universiti Kebangsaan Malaysia Medical Centre, Kuala Lumpur, Malaysia \\ "Corresponding author: Kok-Yong Chin, Department of Pharmacology, Level 17, Preclinical Building, Universiti Kebangsaan Malaysia Medical Centre, Jalan Yaacob Latif, Bandar \\ Tun Razak, 56000 Cheras, Kuala Lumpur, Malaysia. Tel: +603-91459573, Fax: +603-91459547, E-mail: chinkokyong@ppukm.ukm.edu.my
}

Received 2016 October 14; Revised 2016 November 28; Accepted 2017 January 04.

\begin{abstract}
Background: Testosterone deficiency is linked to low-grade inflammation in humans, but this condition is not replicated in an animal study. The current study aims at determining the effects of testosterone deficiency and its replacement on the circulating inflammatory cytokine level in orchidectomized male rats.

Methods: Three-month-old Sprague-Dawley male rats $(n=18)$ were randomized equally into 3 groups. Bilateral orchidectomy was performed on 2 groups. The sham group was subjected to similar surgical stress, but their testes were retained. One of the orchidectomized groups received intramuscular injection of $7 \mathrm{mg} / \mathrm{kg}$ testosterone enanthate suspended in peanut oil weekly and the other 2 groups received equivolume of peanut oil injection. After 8 weeks, the rats were sacrificed and their blood was collected for the analysis of the levels of inflammatory cytokines and testosterone.

Results: Testosterone level was significantly lower in the untreated orchidectomized group compared to the sham group. Testosterone replacement significantly increased the level of testosterone in the orchidectomized rats compared to the sham and untreated orchidectomized rats. Interleukin-1 alpha (IL-1 $\alpha$ ), interleukin-1 beta (IL-1 $\beta$ ), and tumor necrosis factor alpha (TNF $\alpha$ ) showed an increasing trend in orchidectomized rats, albeit not statistically significant. Interleukin-6 (IL-6) level increased significantly in the orchidectomized group compared to the sham group. Testosterone replacement at the supraphysiological dose did not alter the level of inflammatory cytokines significantly in orchidectomized rats.

Conclusions: Testosterone deficiency can elicit a state of low-grade inflammation, shown by an increase in interleukin-6 level, but exogenous supraphysiological testosterone replacement does not suppress the inflammation.
\end{abstract}

Keywords: Androgen, Cytokines, Interleukin-1, Interleukin-6, Tumor Necrosis Factor Alpha

\section{Background}

Production and bioavailability of testosterone in males decrease as their age progresses (1). There is a parallel elevation in low-grade inflammation, as reflected by increased pro-inflammatory cytokines, in aging males (2). Previous studies suggested that testosterone exerts immunosuppressive effects on the body (3). Testosterone could downregulate the expression of toll-like receptor 4 (TLR4), a trigger for inflammation, in macrophages in vitro (4). However, the importance of the relationship between inflammation and testosterone deficiency is not limited to the field of immunology. This is because both testosterone deficiency and low-grade inflammation are implicated in various health conditions, such as sarcopenia, arthritis, osteoporosis, and cardiovascular diseases (5-8).

The association between testosterone level and inflammation is explored in human observational studies (9-11), clinical trials (12,13), and animal studies (14-16). Significant inverse relationship between testosterone levels and certain inflammatory cytokines was observed in young and elderly males $(9,10)$. At the same time, no significant difference in inflammatory cytokine levels was found between the male under androgen deprivation therapy and the ones not receiving the therapy (12). Both positive and negative findings are reported in trials studying the suppressive effects of testosterone on inflammatory cytokines $(12,13)$. The heterogeneity of the results could be due to the subjects and the dose of testosterone used. A preclinical model could be useful in studying the various medical conditions with low-grade inflammation induced by testosterone deficiency.

The current study determined the effects of testosterone deficiency and supraphysiological supplementation of testosterone on inflammatory cytokine levels in orchidectomized rats. Orchidectomy is the most common method of inducing testosterone deficiency in animal. Testosterone has a half-life of 2 days in rats (17). Eight weeks after orchidectomy, depletion of testosterone in rats affected non-sexual organs sensitive to sex hormone, such as muscle and bone $(18,19)$. It was hypothesized that testosterone deficiency would cause a state of low-grade inflam- 
mation in orchidectomized rats, and testosterone supplementation would reverse this effect.

\section{Methods}

The study protocol was reviewed and approved by animal ethics committee of Universiti Kebangsaan Malaysia (approval code: FP/FAR/2012/IMA/18-JULY/445-JULY-2012APRIL-2014). Eighteen 3-month-old Sprague-Dawley rats were obtained from the Laboratory Animal Resource Unit, Universiti Kebangsaan Malaysia (Kuala Lumpur, Malaysia). They were housed at the animal laboratory of department of pharmacology under standard conditions $\left(27^{\circ} \mathrm{C}\right.$, ambient humidity, natural dark/light cycle, standard rat chow as food and tap water ad libitum). They were acclimatized for 1 week before being randomized equally into 3 groups, ie, sham-operated $(\mathrm{SH})(\mathrm{n}=6)$, orchidectomy (ORX) $(\mathrm{n}=$ $6)$ and testosterone enanthate-treated (TE) groups $(n=6)$. The ORX and the TE groups underwent bilateral orchidectomy under general anesthesia (ketamine/xylazine at 100 $\mathrm{mg} / \mathrm{kg}$ : $10 \mathrm{mg} / \mathrm{kg}$, i.p). The SH group underwent similar surgical stress, but their testes were retained. The TE group received weekly intramuscular testosterone enanthate injection $(7 \mathrm{mg} / \mathrm{kg}$ ) diluted in peanut oil, while, the other groups received equivolume of peanut oil injection per se. After 8 weeks of treatment, the rats were euthanized by ketamine/xylazine (300 mg/kg: $30 \mathrm{mg} / \mathrm{kg}$; i.p) and their blood was collected via cardiac puncture in plain tubes.

Blood was centrifuged at $3000 \mathrm{rpm}$ for 10 minutes at $4{ }^{\circ} \mathrm{C}$ to separate serum. The serum was stored at $-70^{\circ} \mathrm{C}$ until analysis. The levels of interleukin-1 alpha (IL-1 $\alpha$ ), interleukin-1 beta (IL-1 $\beta$ ), interleukin-6 (IL-6) and tumor necrosis factor alpha (TNF- $\alpha$ ) were determined using Procarta $₫$ multiplex immunoassay (Affymetrix, Santa Clara, USA). This assay could quantify all 4 cytokines simultaneously, using florescent-dyed microspheres (beads) conjugated with antibodies specific to each cytokine. The beads would pass through laser beams in a flow cytometer. A Luminex® analyzer (Bio-Rad, Hercules, USA) was used to determine the luminescence proportional to each of the analysts in the assay. Antibodies specific to the rat were used. Testosterone level was measured using a conventional enzyme-linked immunoassay (ELISA) kit coated with antibodies specific to rat testosterone (Cusabio, Wuhan, China). Quantification was based on the competition inhibition reaction between the antibody with unlabeled testosterone and horseradish peroxidaseconjugated testosterone. The intra-assay coefficient of variation was $3.9 \%$ for IL- $1 \alpha, 4.0 \%$ for IL- $1 \beta, 3.3 \%$ for IL-6, $1.2 \%$ for $\mathrm{TNF} \alpha$, and $<15 \%$ for testosterone. The inter-assay coefficient of variation (CV) was 3.3\% for IL- $1 \alpha, 3.7 \%$ for IL- $1 \beta$, $2.5 \%$ for IL-6, $4.0 \%$ for TNF $\alpha$, and $<15 \%$ for testosterone.
The detection limit for each assay was $0.1 \mathrm{pg} / \mathrm{mL}$ for IL- $1 \alpha$, $0.5 \mathrm{pg} / \mathrm{mL}$ for IL-1 $\beta, 6.5 \mathrm{pg} / \mathrm{mL}$ for IL-6, $0.7 \mathrm{pg} / \mathrm{mL}$ for TNF $\alpha$, and $0.13 \mathrm{ng} / \mathrm{mL}$ for testosterone. Testosterone depletion was considered successful when a statistically significant difference was observed in testosterone level between $\mathrm{SH}$ and ORX rats.

Statistical analysis was performed using statistical package for social sciences (SPSS) version 20 (IBM, Armonk, USA). Normality of the data was assessed using the ShapiroWilk test. Comparison of testosterone and inflammatory cytokine levels between the 3 groups was performed using one-way analysis of variance (ANOVA) with Tukey's (homogeneity assumed) or Dunnett's T-3 (homogeneity not assumed) post-hoc pair-wise comparison. Data were expressed as mean \pm standard error. Statistical significance was set at $\mathrm{P}<0.05$.

\section{Results}

The testosterone level in the TE group (99.86 \pm 14.00 $\mathrm{ng} / \mathrm{mL}$ ) was significantly higher compared to those of the $\mathrm{SH}(3.21 \pm 0.98 \mathrm{ng} / \mathrm{mL})$ and ORX groups $(0.35 \pm 0.02 \mathrm{ng} / \mathrm{mL})$ $(\mathrm{P}<0.001)$. The $\mathrm{SH}$ group also had higher serum testosterone level compared to the ORX group $(\mathrm{P}=0.023)$ (Figure $1)$.

Figure 1. Serum Testosterone Level in Rats After 8 Weeks

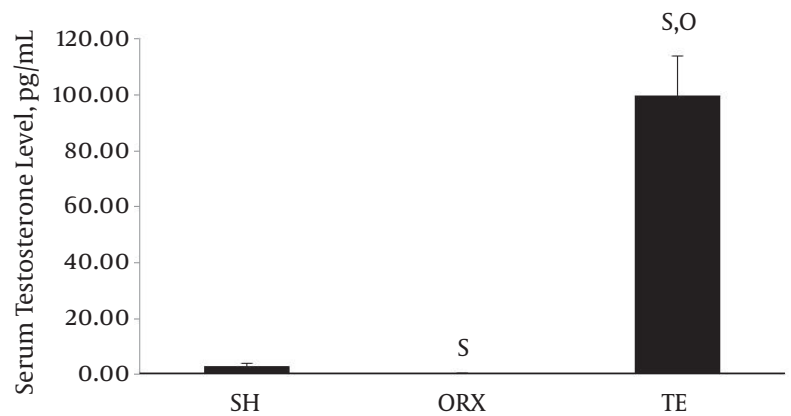

Data are presented as mean \pm standard error. The number of rats per group is 6 . Letter " $\mathrm{s}$ " indicates a significant difference $(\mathrm{P}<0.05)$ compared to sham group, "o" compared to orchidectomized group. Abbreviation: $\mathrm{SH}=$ sham group; $\mathrm{ORX}=$ orchidectomized group; $\mathrm{TE}=$ testosterone enanthate-treated group.

The IL- $1 \alpha(4.33 \pm 0.87 \mathrm{pg} / \mathrm{mL}$ for ORX vs. $2.11 \pm 0.20$ $\mathrm{pg} / \mathrm{mL}$ for $\mathrm{SH} ; \mathrm{P}=0.131)$ and $\beta$ levels $(8.50 \pm 1.46 \mathrm{pg} / \mathrm{mL}$ for ORX vs. $4.18 \pm 0.60 \mathrm{pg} / \mathrm{mL}$ for $\mathrm{SH} ; \mathrm{P}=0.071$ ) appeared to have elevated in the ORX group, but the increase was not statistically significance. The TE and SH groups shared similar levels of IL- $\alpha(2.07 \pm 0.23 \mathrm{pg} / \mathrm{mL}$ for TE vs. $2.11 \pm 0.20$ $\mathrm{pg} / \mathrm{mL}$ for $\mathrm{SH} ; \mathrm{P}=0.998)$ and $\beta(5.35 \pm 1.53 \mathrm{pg} / \mathrm{mL}$ for TE vs. $4.18 \pm 0.60 \mathrm{pg} / \mathrm{mL}$ for $\mathrm{SH} ; \mathrm{P}=0.796$ ) (Figure $2 \mathrm{~A}$ and $\mathrm{B}$ ). 
The level of IL- 6 significantly increased in the ORX group $(26.69 \pm 3.04 \mathrm{pg} / \mathrm{mL})$ compared to the SH group (8.35 \pm $1.19 \mathrm{pg} / \mathrm{mL})(\mathrm{P}=0.017)$ (Figure $2 \mathrm{C})$. Administration of supraphysiological testosterone did not suppress the elevation of IL-6 (32.79 $\pm 2.06 \mathrm{pg} / \mathrm{mL}$; P = 0.891 vs. ORX). TNF $\alpha$ appeared to increase with orchidectomy, albeit not statistically significant $(2.08 \pm 0.44 \mathrm{pg} / \mathrm{mL}$ for ORX vs. $1.30 \pm 0.30$ $\mathrm{pg} / \mathrm{mL}$ for $\mathrm{SH} ; \mathrm{P}=0.401$ ), and testosterone replacement did not suppress this increase $(2.56 \pm 0.47 \mathrm{pg} / \mathrm{mL}$ for TE; $\mathrm{P}=$ 0.692 vs. ORX) (Figure 2D).

\section{Discussion}

The results of the current study indicated that orchidectomy induced a significant increase in IL- 6 in male rats. The levels of TNF $\alpha$, IL- $1 \alpha$, and IL-1 $\beta$ also elevated in orchidectomized rats, but the differences with those of sham were not statistically significant. The current study observations suggested that compared to other cytokines, IL- 6 was the most responsive to changes in testosterone level in vivo. The current study observations were similar with the findings of Freeman et al. They reported that orchidectomized rats with subphysiological testosterone level showed marginal elevated interleukins and TNF $\alpha$ levels compared to those of age-matched rats, but it was not statistically significant (14). In contrast, a study by Steffens et al. showed no significant differences in serum and tissue IL-6 levels between orchidectomized and sham rats $(16,19)$. However, orchidectomized rats with ligature-induced inflammation showed significantly higher tissue IL-1 $\beta$ level compared to ligated sham rats in their study (16). It suggested that testosterone deficiency by itself might not induce strong inflammatory response, but it might exacerbate pre-existing inflammatory conditions. This is in accordance with the immunosuppressive actions of testosterone (4).

In the current study, administration of supraphysiological testosterone appeared to prevent the elevation levels of IL- $1 \alpha$, IL-1 $\beta$, but did not prevent the increase in TNF $\alpha$ and IL-6. Similarly, Freeman et al. also did not observe significant differences in cytokine levels between orchidectomized rats supplemented with physiological $(2.5 \mathrm{mg}$ ) and supraphysiological ( $35 \mathrm{mg}$ ) testosterone for 4 weeks (14). Steffens et al. also found no significant differences in serum and tissue IL-6 levels between orchidectomized rats and the ones receiving high-dose testosterone (250 $\mathrm{mg} / \mathrm{kg}$ testosterone esters weekly) (16). These previous animal studies as well as the current one indicated that exogenous testosterone supplementation might not alter the cytokines production in the body. On the other hand, Mendes et al. showed that the combination of ethanol consumption and testosterone treatment (testosterone cypionate 5 $\mathrm{mg} / \mathrm{kg}$ every other day for 4 weeks) caused a significant increase in TNF $\alpha$, but not IL-6 in rats (15). However, each compound alone did not significantly change the level of cytokines in rats (15). The results of the study by Mendes et al. pointed out that exogenous testosterone supplementation might aggravate the inflammatory properties of other compounds.

In vitro studies showed that testosterone could modify the quantity of cytokines and the peripheral cells producing it. Corcoran et al. showed that physiological (10 nM) and pharmacological (100 nM) testosterone levels significantly reduced the gene and protein expression of TNF $\alpha$ in macrophages derived from males and females (20). Corrales et al. reported that after testosterone treatment, the number of monocytes and dendritic cells producing IL-1, IL-6, and TNF $\alpha$ in aging type 2 diabetic males with partial androgen deficiency became undetectable by flow cytometry (21). However, these changes might not be significant enough to be detected in vivo as the case of the current study.

The current study had some limitations. Sexually matured young rats were used, although aged rats might be better representatives of elderly males. However, orchidectomy ensured that the rats experienced testosterone deficiency that was similar to hypogonadal human subjects. It was a preliminary study on the effects of testosterone on inflammation in an animal model. Only a limited number of cytokines, all of them pro-inflammatory, were evaluated in the current study. However, they are established markers of inflammation involved in the pathogenesis of various health conditions. The mechanistic studies on the effects of testosterone on the quantity of cytokines and their producing cells should be evaluated in further studies. The apparent elevation in cytokine level, which did not reach statistical significance, might be due to small sample size and low power. This could be improved by increasing the number of animal and duration of treatment. Further studies are needed to validate and strengthen the results.

In conclusion, testosterone deficiency increases the pro-inflammatory cytokine, IL-6, but its effects on other cytokines are marginal. High-dose testosterone does not alter the level of inflammatory cytokines. Testosterone deficiency might not be a good model for low-grade inflammation. Further improved studies are needed to validate the association between testosterone deficiency and inflammation.

\section{Acknowledgments}

Authors wish to thank Universiti Kebangsaan Malaysia for funding the study via grants GGPM-2015-036 and FF2016-008. 
Figure 2. Serum Inflammatory Cytokines in Rats After 8 Weeks of Treatment

A

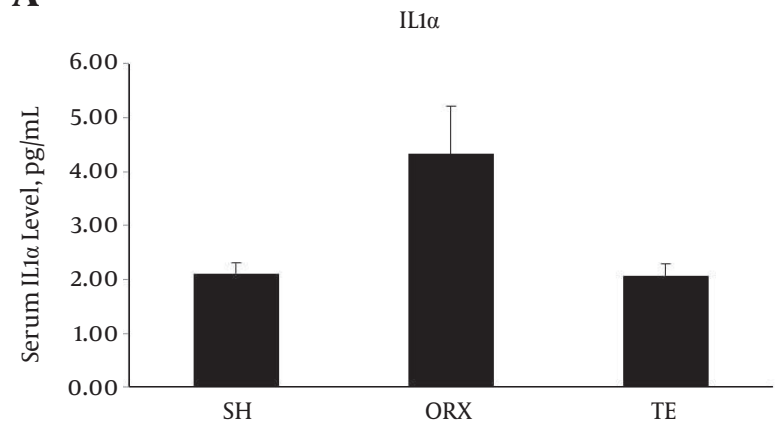

C

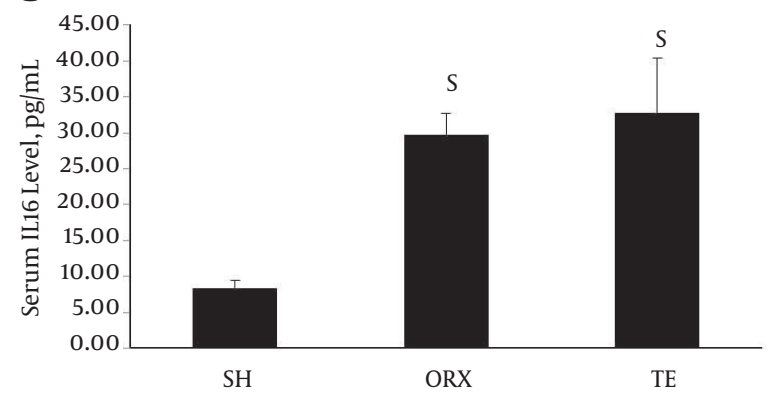

B

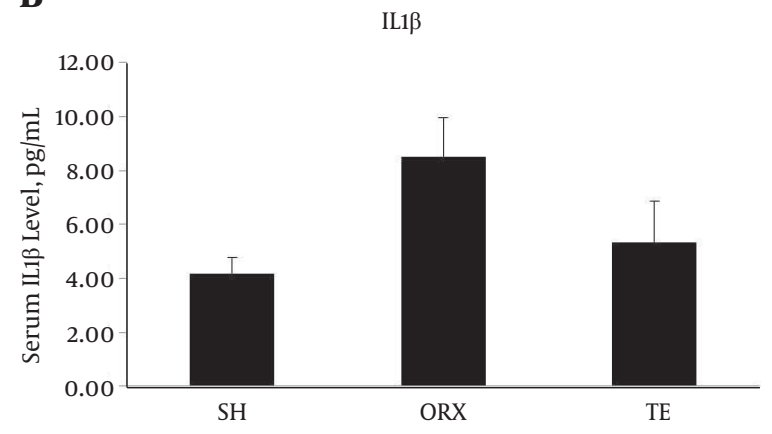

D

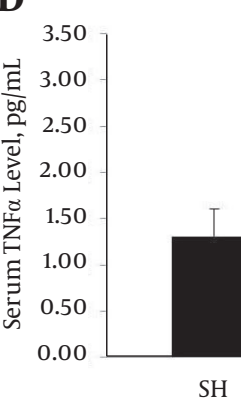

$\mathrm{TNF} \alpha$

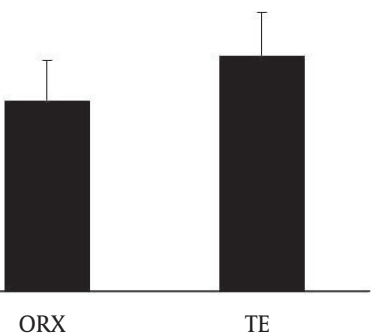

Data are presented as mean \pm standard error. The number of rats per group is 6. Letter "s" indicates a significant difference $(\mathrm{P}<0.05)$ compared to sham group. Abbreviation $\mathrm{SH}=$ sham group; $\mathrm{ORX}=$ orchidectomized group; $\mathrm{TE}=$ testosterone enanthate-treated group.

\section{Footnotes}

Authors' Contribution: Kok-Yong Chin: study design, conducting the experiments, analyzing data, and drafting the manuscript; Soelaiman Ima-Nirwana: providing critical support to secure the funding, supervising the project, and reviewing the manuscript.

Financial Disclosure: The authors declared no conflict of interest under the current study.

Funding/Support: The work was supported by Universiti Kebangsaan Malaysia via grants GGPM-2015-036 and FF2016-008.

\section{References}

1. Chin KY, Soelaiman IN, Mohamed IN, Ahmad F, Ramli ES, Aminuddin A, et al. Sex hormones in Malay and Chinese men in Malaysia: are there age and race differences?. Clinics (Sao Paulo). 2013;68(2):159-66. [PubMed: 23525310].

2. Ferrucci L, Corsi A, Lauretani F, Bandinelli S, Bartali B, Taub DD, et al. The origins of age-related proinflammatory state. Blood. 2005;105(6):2294-9. doi: 10.1182/blood-2004-07-2599. [PubMed: 15572589].
3. Sasaki M, Fujii Y, Iwamoto M, Ikadai H. Effect of sex steroids on Babesia microti infection in mice. Am J Trop Med Hyg. 2013;88(2):367-75. doi: 10.4269/ajtmh.2012.12-0338. [PubMed: 23249689].

4. Rettew JA, Huet-Hudson YM, Marriott I. Testosterone reduces macrophage expression in the mouse of toll-like receptor 4, a trigger for inflammation and innate immunity. Biol Reprod. 2008;78(3):432-7. doi: 10.1095/biolreprod.107.063545. [PubMed: 18003947].

5. Ginaldi L, Di Benedetto MC, De Martinis M. Osteoporosis, inflammation and ageing. Immun Ageing. 2005;2:14. doi: 10.1186/1742-4933-2-14. [PubMed: 16271143].

6. Singh $\mathrm{T}$, Newman AB. Inflammatory markers in population studies of aging. Ageing Res Rev. 2011;10(3):319-29. doi: 10.1016/j.arr.2010.11.002. [PubMed: 21145432].

7. Chin KY, Soelaiman IN, Naina Mohamed I, Shahar S, Teng NI, Suhana Mohd Ramli E, et al. Testosterone is associated with age-related changes in bone health status, muscle strength and body composition in men. Aging Male. 2012;15(4):240-5. doi: 10.3109/13685538.2012.724740. [PubMed: 23098182].

8. Oskui PM, French WJ, Herring MJ, Mayeda GS, Burstein S, Kloner RA. Testosterone and the cardiovascular system: a comprehensive review of the clinical literature. JAm Heart Assoc. 2013;2(6):000272. doi: 10.1161/JAHA.113.000272. [PubMed: 24242682].

9. Bobjer J, Katrinaki M, Tsatsanis C, Lundberg Giwercman Y, Giwercman A. Negative association between testosterone concentration and inflammatory markers in young men: a nested cross-sectional study. PLoS One. 2013;8(4):61466. doi: 10.1371/journal.pone.0061466. [PubMed: 23637840]. 
10. Maggio M, Basaria S, Ble A, Lauretani F, Bandinelli S, Ceda GP, et al. Correlation between testosterone and the inflammatory marker soluble interleukin-6 receptor in older men. J Clin Endocrinol Metab. 2006;91(1):345-7. doi:10.1210/jc.2005-1097. [PubMed:16263825].

11. Maggio M, Blackford A, Taub D, Carducci M, Ble A, Metter EJ, et al. Circulating inflammatory cytokine expression in men with prostate cancer undergoing androgen deprivation therapy. $J$ Androl. 2006;27(6):725-8. doi: 10.2164/jandrol.106.000141. [PubMed: 16775253].

12. Maggio M, Snyder PJ, De Vita F, Ceda GP, Milaneschi Y, Lauretani F, et al. Effects of transdermal testosterone treatment on inflammatory markers in elderly males. Endocr Pract. 2014;20(11):1170-7. doi: 10.4158/EP13357.OR. [PubMed: 25100359].

13. Malkin CJ, Pugh PJ, Jones RD, Kapoor D, Channer KS, Jones TH. The effect of testosterone replacement on endogenous inflammatory cytokines and lipid profiles in hypogonadal men.JClin Endocrinol Metab. 2004;89(7):3313-8. doi:10.1210/jc.2003-031069. [PubMed: 15240608].

14. Freeman BM, Mountain DJ, Brock TC, Chapman JR, Kirkpatrick SS, Freeman MB, et al. Low testosterone elevates interleukin family cytokines in a rodent model: a possible mechanism for the potentiation of vascular disease in androgen-deficient males. J Surg Res. 2014;190(1):31927. doi: 10.1016/j.jss.2014.03.017. [PubMed: 24703604].

15. Mendes LO, Scarano WR, Rochel-Maia SS, Fioruci-Fontaneli BA, Chuffa LG, Martinez FE. Testosterone therapy differently regulates the antiand pro-inflammatory cytokines in the plasma and prostate of rats submitted to chronic ethanol consumption (UChB). Am J Reprod Im- munol. 2014;72(3):317-25. doi: 10.1111/aji.12268. [PubMed: 24828842].

16. Steffens JP, Herrera BS, Coimbra LS, Stephens DN, Rossa CJ, Spolidorio $\mathrm{LC}$, et al. Testosterone regulates bone response to inflammation. Horm Metab Res. 2014;46(3):193-200. doi: 10.1055/s-0034-1367031. [PubMed: 24526374].

17. James KC, Nicholls PJ, Roberts M. Biological half-lives of [4$14 \mathrm{C}$ ]testosterone and some of its esters after injection into the rat. J Pharm Pharmacol. 1969;21(1):24-7. [PubMed: 4388185].

18. Moreau MF, Libouban H, Legrand E, Basle MF, Audran M, Chappard D. Lean, fat and bone masses are influenced by orchidectomy in the rat. A densitometric X-ray absorptiometric study.J Musculoskelet Neuronal Interact. 2001;1(3):209-13. [PubMed: 15758494].

19. Chin KY, Ima-Nirwana S. The effects of orchidectomy and supraphysiological testosterone administration on trabecular bone structure and gene expression in rats. Aging Male. 2015;18(1):60-6. doi: 10.3109/13685538.2014.954995. [PubMed: 25166624].

20. Corcoran MP, Meydani M, Lichtenstein AH, Schaefer EJ, Dillard A Lamon-Fava S. Sex hormone modulation of proinflammatory cytokine and C-reactive protein expression in macrophages from older men and postmenopausal women. J Endocrinol. 2010;206(2):217-24. doi: 10.1677/JOE-10-0057. [PubMed: 20484148].

21. Corrales JJ, Almeida M, Burgo R, Mories MT, Miralles JM, Orfao A. Androgen-replacement therapy depresses the ex vivo production of inflammatory cytokines by circulating antigen-presenting cells in aging type-2 diabetic men with partial androgen deficiency.JEndocrinol. 2006;189(3):595-604. doi: 10.1677/joe.1.06779. [PubMed: 16731790]. 